\title{
Euskal Autonomia Erkidegoan kokatuta dauden eraikinen birgaitze energetikoa: birgaitze-teknikak eta erabakia hartzeko jasangarritasun-irizpideak
}

\author{
(Energy Saving retrofit of buildings in the Basque Country: \\ Retrofit solutions and sustainable criteria for decision-making)
}

\author{
Ziortza Egiluz*, Jesús Cuadrado, Eduardo Rojí, Ugaitz, Gaztelu \\ Department of Mechanical Engineering, School of Engineering, \\ University of the Basque Country (UPV/EHU)
}

LABURPENA: Eraikuntzako energia-kontsumoak gora egin du azken urteotan. Horregatik, eraikinen energia-efizientziari buruzko araudiak ezarri behar izan dira kontsumoa kontrolatzeko, energia-aurrezpena hobetzeko eta energia-efizientzia hobetzeko. Baina Euskal Autonomia Erkidegoan oso handia denez eraikin zahar eta energetikoki pobreen kopurua, behar-beharrezkoa da eraikin horietan esku hartzea eta epe labur edo ertainean energetikoki birgaitzea.

Birgaitze-teknikarik egokiena aukeratzea ez da lan erreza, eraikuntza-soluzio ugari baitaude eraikinak energetikoki birgaitzeko. Hori dela eta, erabakia hartzen laguntzeko, jasangarritasunirizpideak erabiltzea planteatzen da. Horrela, birgaitze-teknikak ekonomiaren, ingurumenaren eta gizartearen ikuspegitik aztertuko dira.

HITZ GAKOAK: fatxada, jasangarritasuna, birgaitzea, energia-efizientzia.

ABSTRACT: Energy consumption in buildings has increased in recent years. That is why it has become necessary to establish regulations regarding the energy efficiency of buildings to control consumption, improve energy savings and energy efficiency. Nevertheless, the large volume of old and energy-poor buildings in Basque Autonomous Community makes it necessary to intervene in these, retrofitting them in the short or medium term.

There are a great variety of constructive solutions to retrofit buildings energetically, which makes it difficult to choose the most suitable solution. Therefore, to help decision-making, the use of sustainability criteria is proposed. In this way, it is proposed to evaluate rehabilitation techniques from an economic, environmental and social point of view.

KEYWORDS: Façades, sustainability, retrofit, energy efficiency.

\footnotetext{
* Harremanetan jartzeko / Corresponding author: Ziortza Egiluz, UPV/EHU, Torres Quevedo Enparantza, 1 (48013 Bilbo, Bizkaia, Euskal Herria). - ziortza.egiluz@ehu.eus - https://orcid.org/0000-0003-3366-8042.

Nola aipatu / How to cite: Egiluz, Ziortza; Cuadrado, Jesús; Rojí, Eduardo; Gaztelu, Ugaitz (2022). «Euskal Autonomia Erkidegoan kokatuta dauden eraikinen birgaitze energetikoa: birgaitze-teknikak eta erabakia hartzeko jasangarritasun-irizpideak»; Ekaia, ale berezia 2022, 31-47. (https://doi.org/10.1387/ekaia.23101)

Jasotze-data: 2021, irailak 30; Onartze-data: 2022, abenduak 28

ISSN 0214-9001 - eISSN 2444-3255 / (c) 2022 UPV/EHU
}

(i) $\odot$ Lan hau Creative Commons Aitortu-EzKomertziala-LanEratorririkGabe 4.0 Nazioartekoa lizentzia baten mende dago 


\section{SARRERA}

Europar Batasunean, azken energia-kontsumoaren ia \% 50a berotzeeta hozte-sistemetara bideratzen da. Eraikinek horren \% 80a kontsumitzen dute [1] eta $\mathrm{CO}_{2}$ isurketen \% 36a eragiten dute [1,2]. Europaren energiainportazioekiko mendekotasuna eta energia-baliabideen eskasia gero eta handiagoak dira. Gainera, etxeetako kontsumo-ohiturek eta ekipamendu progresiboak igoarazi egin dute energia-eskaria bizitegi-sektorean [3]. Horrek aldaketak eragin ditu Europako zuzentarauetan eta, beraz, Estatuko eta Euskal Autonomia Erkidegoko araudietan. Aldaketa horiek direla eta, areagotu egin dira energia-efizientziari dagokionez eraikinek bete behar dituzten eskakizun termikoak. Horrela, energia-kontsumoa kontrola daiteke, energia-aurrezpena eta energia-efizientzia susta daitezke, eta iturri berriztagarrietatik sortutako energiaren erabilera ere bultza daiteke.

Eraikuntzaren sektorea sektore estrategiko bihurtu da. Izan ere, sektore horrek du, garraioaren eta industriaren sektoreekin batera, aurrezteko ahalmen handiena [4]. Baina eraikinen eraispen-tasa baxua da, eta eraikin berrien hazkunde-tasa txikia. Hortaz, eraikinetan lortu nahi den eta exijitzen den energiaren eta $\mathrm{CO}_{2}$ emisioen aurreztea eraikinak energetikoki birgaituz lortu beharko da $[2,5]$.

1973. urtean mundu-mailan eman zen lehen energia-krisiaren ondorioz, eraikinen isolamendu termikoa kontuan hartu zuen lehen eraikuntza-araua onetsi zen Espainian (NBE-CT-79, Eraikingintzako Oinarrizko Araua). Arau hori 1980an jarri zen indarrean; beraz, urte hori baino lehen eraikitako eraikinek ez zuten inguratzailearen isolamendu termikoari buruzko araudia bete beharrik. Eraikin horiek ez zuten isolamendurik fatxadetan, ez eta estalkietan ere. Normalean, leihoak beira sinplekoak izaten ziren, eta zurezko arotzeria eta pertsianak izaten zituzten. Horrek galera termiko handiak eragiten zituen eraikinaren inguratzailean [6]. Baina efizientzia energetikoari buruzko 2002/91/EE Europako Zuzentarauaren transposizioak indargabetu egin zuen arau hori, eta 2006an Eraikingintzaren Kode Teknikoa (EKT) onartu zen [7]. Araudi horrek, Energia Aurrezteko Oinarrizko Dokumentuaren (DB HE, gaztelaniako siglak) HE1 atalean, eraikinaren eskaera energetikoaren muga ezartzen du. Bertan, efizientzia energetikoaren arloko arau zorrotzagoak xedatzen dira. EKT eguneratu egin zen 2013an, eraikinen efizientzia energetikoari buruzko 2010/31/EB Zuzentarauaren transposizioa egiteko Espainiako arau-esparrura. 2019an berriro eguneratu zen, efizientzia energetikoaren gutxieneko baldintzak berrikusi eta eguneratu egin behar direlako aldizka [8]. EKTn eraikinen inguratzaile termikoak bete beharreko gutxieneko baldintzak xedatzen dira, eraikina kokatuta dagoen udalerriko klima-zonaren arabera (1. irudia) [8]. Klima-zonak udalerrietako neguko eta udako klimaren zorroztasunaren arabera ezartzen dira. Neguko klimaren gogortasuna letra baten bidez ezartzen da (A-E), eta udako klimaren gogortasuna zenbaki baten bidez (1-4). 


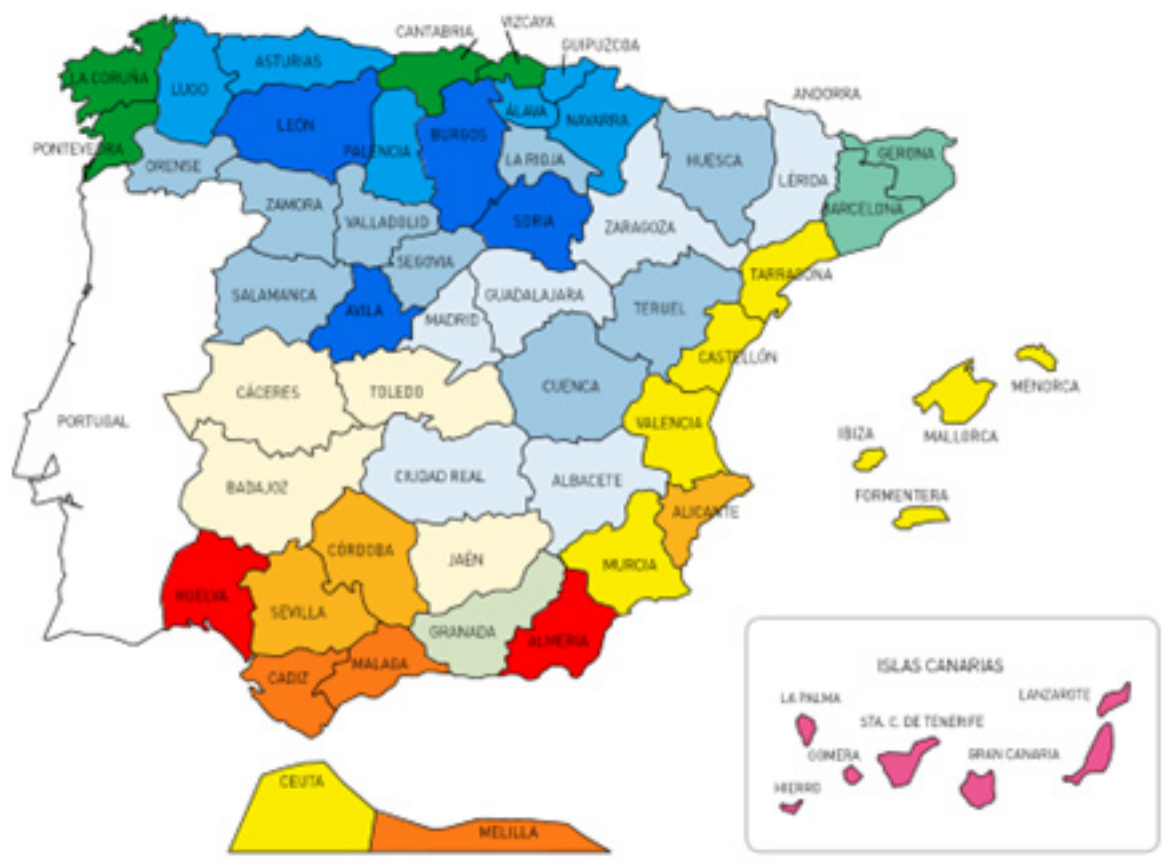

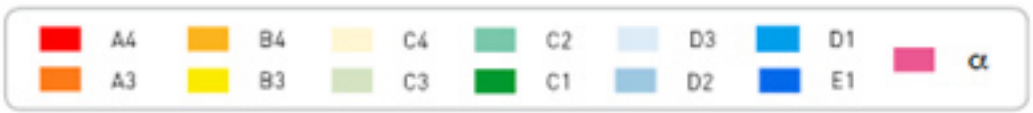

1. irudia. EKTk xedatutako klima-zonak Espainian, neguko eta udako zorroztasunaren arabera.

1. irudian ikus daitekeen bezala, Euskal Autonomia Erkidegoa (EAE) neguko hiru klima-zonatan banatuta dago: C, D eta E. Udako klima-zona, aldiz, berdina da guztientzat: 1 .

EKTren Energia Aurrezteko Oinarrizko Dokumentuaren arabera, birgaitutako eraikinaren energia-eskariak txikiagoa izan beharko du erreferentziako eraikinarenak baino, eraikina kokatuta dagoen klima-zonaren arabera. 1. taulan transmitantzia termikoaren balioak ikus daitezke, EAEko klima-zonen arabera. 
1. taula. Kanpoko airearekin kontaktuan dauden horma eta zoruen gutxieneko transmitantzia termikoa, EAEko probintzien klima-zonaren arabera.

\begin{tabular}{lcc}
\hline $\begin{array}{c}\text { EAEko probintzietako } \\
\text { hiriburuak }\end{array}$ & Klima-zona & $\begin{array}{c}\text { Kanpoko airearekin kontaktuan dauden horma } \\
\text { eta zoruen gutxieneko transmitantzia termikoa }\end{array}$ \\
\hline Bilbo & C1 & $0,49 \mathrm{~W} / \mathrm{m}^{2} \mathrm{~K}$ \\
Donostia & D1 & $0,41 \mathrm{~W} / \mathrm{m}^{2} \mathrm{~K}$ \\
Gasteiz & D1 & $0,41 \mathrm{~W} / \mathrm{m}^{2} \mathrm{~K}$ \\
\hline
\end{tabular}

\section{EAE-ko ETXEBIZITZA-PARKEA}

Euskal Autonomia Erkidegoko etxebizitza-parkea zehazteko, Estatistikako Institutu Nazionalaren (INE, gaztelaniako siglak) estatistikak hartu dira oinarritzat. Errolda berriena 2011 ko biztanleriaren eta etxebizitzen errolda da [9], zeina hamar urtean behin egiten den.

2. irudian ikus daitekeen bezala, EAEn nagusiki edo soilik etxebizitzetarako ziren eraikinen \% 43 1961a baino lehen eraiki ziren. Beraz, dauden eraikinen ia erdiek 50 urtetik gorako antzinatasuna dute.

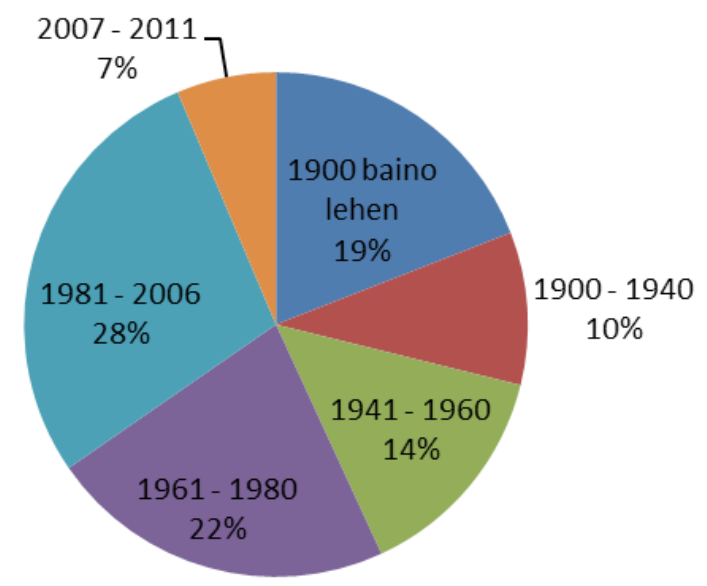

2. irudia. EAEn dauden etxebizitzen banaketa, eraikin ziren urtea kontuan hartuta.

Gaur egun eraikita duden eraikinen \% 65 inguru 1980a baino lehen eraiki ziren; beraz, ez dute isolamendu termikorik. Izan ere, eraiki zirenean, ez zegoen eraikinen isolamendu termikoari buruzko eskakizunak jasotzen zituen araudirik - NBE-CT-79 araua 1980an jarri zen indarrean-. Era berean, nagusiki edo soilik etxebizitzetarako diren eraikinen \% 90 
Euskal Autonomia Erkidegoan kokatuta dauden eraikinen birgaitze energetikoa: birgaitze-teknikak eta erabakia hartzeko jasangarritasun-irizpideak

baino gehiago - jada birgaituta dauden eraikinak kontuan hartu gabe - pobreak dira energetikoki. Eraikin horiek, izan ere, efizientzia energetikoari buruzko gutxieneko eskakizunak jasotzen dituen araudia (2006ko EKT) indarrean jarri baino lehen eraiki ziren. Hortaz, epe luzean edo laburrean, birgaitu egin beharko dira eraikin horiek.

EUSTATek (Euskal Estatistika Erakundea) 2020an EAEko familiaetxebizitzei buruz emandako datuen arabera [10], EAEko etxebizitzen batez besteko antzinatasuna 46,2 urtekoa da. Probintzien arabera, Bizkaia da etxebizitza zaharrenak dituen probintzia ( 47,8 urte, batez beste), eta ondoren Gipuzkoa (46,7 urte) eta Araba (39,7 urte) daude.

BPIE (Buildings Performance Institute Europe) erakundearen Europe's Buildings under the microscope txosteneko datuen arabera, EAEko etxebizitza-parkea Europa Hegoalde osoko zaharrena da [11], eta Europar Batasun osoko zaharrenetakoa, Erresuma Batuaren atzetik [12].

Era berean, 1998-2021 artean EAEn emandako obra handiko lizentziak (obra berriko lizentziak eta birgaitzeko lizentziak) [10] kontuan hartuta, ikusten da eraikin berriak egiteko joerak behera egin duela urteetan zehar, eta birgaitzeko lanek, aldiz, gora egin dutela, eraikuntza berriek baino neurri handiago batean (3. irudia).

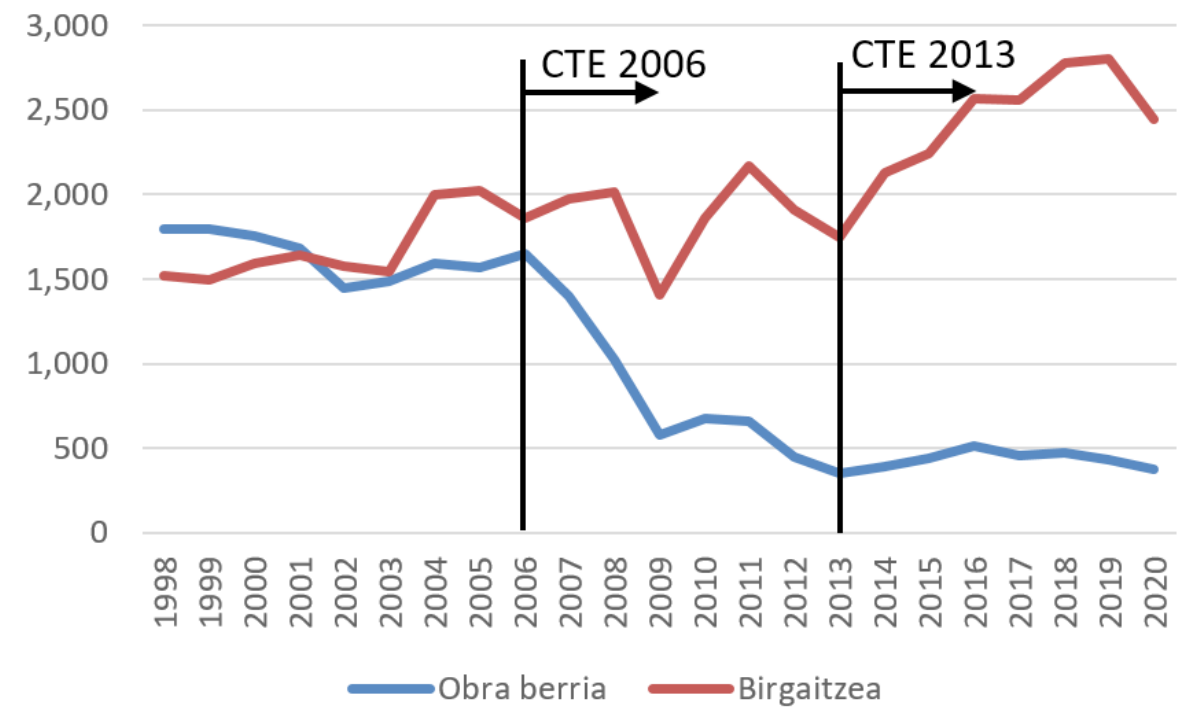

3. irudia. Obra handien lizentziak EAEn, urtez urte.

Birgaitze-lizentziak ez dakar esplizituki eraikinen efizientzia energetikoa hobetzea. Baina EKTn 2013an egindako aldaketarekin, zabaldu egin da 
energia-eskaera mugatzeko aplikazio-eremua. Hortaz, arau hori bete behar da bai lehendik eraikita dauden eraikinak handitzean, bai eraberritzean edo bai erabilera-aldaketa bat egitean. Beraz, 2013tik aurrera, emandako birgaitze-lizentziek hobetu egiten dute lehendik dauden eraikinen efizientzia energetikoa. Era berean, EKTn 2006an ezarritako aplikazio-eremuari erreparatuta, 2006 eta 2013 artean emandako obra-lizentzia askok hobetu egin dute birgaitutako eraikinen energia-efizientzia.

Azken urteetan birgaitzeko lizentzietan eman den gorakada Espainian eta EAEn eraikinen birgaitzea sustatzeko hartu diren neurriengatik izan da. Horren adibide bat «Plan de Recuperación, Transformación y Resiliencia de la Economía española» [13] da. Plan horren barruan, «Programa de Rehabilitación de Vivienda y Regeneración Urbana» dago. Programa horrek 6.820 milioi euroko aurrekontua du, 2021-2023 bitartean eraikinak energetikoki birgaitzeko. Aurrekontua eraikin pribatu zein publikoetarako da. Horrekin, energia aurreztea eta isuriak murriztea sustatzen da.

Etxebizitzetan birgaitze energetikoak ahalbidetzen duen energia-aurrezpena zehazteko kontuan hartu beharreko datu bat berotze- eta hozte-sistemen energia-kontsumoa da. EAEn, bertako klimaren ezaugarriak eta lurraldearen kokapena kontuan hartuta, ez da behar hozte-sistemarik. Lurraldeko batez besteko tenperatura $21,3{ }^{\circ} \mathrm{C}$-koa da udan, EUSTATek 2015ean ingurumenari eta familiei buruz emandako datu estatistikoen arabera [14]. Halaber, inkesta horren arabera, EAEko etxebizitzen \% 1,7k baino ez du aire girotuko instalazioa. Beraz, birgaitze-teknikak planteatzerakoan, ez da kontuan hartuko etxebizitzetako hozte-kontsumoa.

Era berean, EAEko etxebizitzen batez besteko azalera erabilgarria $87,3 \mathrm{~m}^{2}$-koa da, EUSTATek familia-etxebizitzei buruz 2020an emandako datuen arabera [10]. Bestalde, EAEn salgai dauden erabilitako etxebizitzen azalera $\left(\mathrm{m}^{2}\right)$ erabilgarriaren batez besteko prezioa 2.765 eurokoa da 2021eko bigarren hiruhilekoan.

Batez besteko azalera erabilgarriari eta bere prezioari buruzko datuak garrantzitsuak izango dira birgaitze-sistema egokiena aukeratzeko orduan, barruko isolamendu-sistemek espazio erabilgarria galtzea baitakarte.

Kontuan hartu beharreko beste datu bat etxebizitzaren edukitzaerregimena da. Izan ere, eraikinean birgaitzeko obra bat egin ahal izateko, jabeen adostasuna behar da. Obra osoa jabeek ordaintzen dute, gainera. Jabetza Horizontalari buruzko uztailaren 21eko 49/1960 Legean (2015ean aldatu zen) [15] xedatutakoaren arabera, eraikinaren egitura eta kanpoko egoera edozein modutan aldatzeko, beharrezkoa da komunitateko kide guztien adostasuna. Beraz, eraikina birgaitzeko erabiliko den teknikak eraikinaren kanpoko egoera aldatzen badu, jabeen arteko ados- 
Euskal Autonomia Erkidegoan kokatuta dauden eraikinen birgaitze energetikoa: birgaitze-teknikak eta erabakia hartzeko jasangarritasun-irizpideak

tasuna beharko da. EUSTATek [10] emandako datuen arabera, EAEn etxebizitza jabetzan erostekoa edo edukitzekoa da joera nagusia. Izan ere, 2016an jabetzako etxebizitzak \% 87 inguru ziren, alokairuko etxebizitzen aldean.

\section{BIRGAITZE JASANGARRIA}

Eraikinen birgaitze energetikoaren prozesua hainbat hobekuntzaneurriren bidez egin daiteke. Espainian, inbertsioaren euro bakoitzeko $\mathrm{CO}_{2}$ isurketen murrizketa handiena lortzen dutenak hauek dira: eraikinaren inguratzailearen efizientzia termikoa hobetzea (fatxada eta estalkia), leihoen portaera termikoa hobetzea eta, azkenik, instalazio termikoak hobetzea, efizientzia handiko galdarak, biomasa edo beste energia-iturri berriztagarri bat erabiliz [16]. Bestalde, hobekuntza-neurri horien bidez etxebizitzen batez besteko kontsumoan lortzen den murrizketari begiratzen bazaio, eraikinaren inguratzaile termikoa isolatuz $\% 57$ eta $\% 72$ arteko aurrezpena lortzen da, \% 12,4koa ekipo termikoak soilik hobetuz, eta \% 23,2koa instalazioak iturri berriztagarriko sistemen bidez hobetuz [17]. Horregatik, eraikinen energia-kontsumoa murrizteko funtsezko hobekuntza-neurri bat fatxadaren portaera termikoa hobetzea da [18]; izan ere, eraikinaren guztizko kontsumoaren $\% 50$ inguru inguratzailean gertatzen da [19].

Baina hainbat teknika daude eraikinen fatxada birgaitzeko. Gainera, birgaitze-teknikak alderdi ekonomikoak eta ingurumenekoak kontuan hartuta ebaluatu behar dira [20]. Dena den, birgaitzeko soluzio optimoak faktore tekniko eta sozialen konbinazioa ere izan beharko du [5]. Izan ere, eraikinak birgaitzea oso garrantzitsua da, berehalako ondorioengatik ez ezik (energia-kontsumoa murriztea, eraikinen egoera hobetzea, eta abar), epe luzeko ondorio positiboengatik ere, hala nola bizi-kalitatea handitzea, ingurumen-inpaktua murriztea, eta abar. Eraikinak giza espazioak dira, eta bertan bizi eta lan egiten da. Horregatik, kontuan hartu behar da eraikitako eta giza ingurunearen berrikuntza [21]. Hau da, eraikina birgaitzeko orduan, jasangarritasunaren funtsezko hiru oinarriak hartu behar dira kontuan: ekonomia, ingurumena eta gizartea.

Hortaz, lan honetan, birgaitze-teknika egokiena aukeratzeko, jasangarritasun-irizpideak erabiltzea planteatzen da. Horrela, jasangarritasunaren ikuspuntutik ebaluatuko ditu birgaitze-teknikak. Gainera, eraikin baten birgaitze-prozesuan soluziorik egokiena eta jasangarriena aukeratzen lagunduko du. 2. taulan, birgaitze jasangarria lortzeko jasangarritasunaren funtsezko hiru oinarriak eta horietako bakoitzari lotutako irizpide batzuk agertzen dira $[6,22]$. 
2. taula. Jasangarritasunaren funtsezko oinarriak eta birgaitze-jasangarri batean aplikatu beharreko irizpideak.

\begin{tabular}{c|l}
\hline Oinarriak & \multicolumn{1}{c}{ Irizpideak } \\
\hline \multirow{4}{*}{ Ekonomia } & $\begin{array}{l}\text { Materialen kostua } \\
\text { Instalazioaren kostua } \\
\text { Mantenuaren urteroko kostua }\end{array}$ \\
\cline { 2 - 2 } & $\begin{array}{l}\text { Inbertsioaren errentagarritasuna } \\
\ldots\end{array}$ \\
\hline \multirow{5}{*}{ Ingurumena } & $\begin{array}{l}\text { Birziklagarritasuna } \\
\text { Cortutako hondakinak }\end{array}$ \\
\cline { 2 - 2 } & Ingurumen-inpaktua \\
\cline { 2 - 2 } & Konfort termikoa \\
& $\ldots$ \\
\hline \multirow{5}{*}{ Gizartea } & Etxebizitza uzteko beharra \\
\cline { 2 - 3 } & Instalazioaren ondorengo espazio-galera \\
\cline { 2 - 3 } & Aldamioen beharra \\
\cline { 2 - 3 } & Jabeen arteko adostasunaren beharra \\
\cline { 2 - 3 } & Ondare arkitektonikoa \\
\hline
\end{tabular}

Era honetan planteatzen diren jasangarritasun-irizpideak lan-tresna bezala erabil daitezke. Lan-tresna honek jasangarritasunaren ikuspuntutik egokiena den birgaitze-teknika aukeratzen lagunduko du. Birgaitze-prozesuan parte hartzen duten eragile guztiei zuzenduta dago, bai eraikinen jabeei eta bai eraikuntza-enpresei.

\section{BIRGAITZE-TEKNIKAK}

Fatxadak birgaitzeko dauden birgaitze-metodoak teknika kontrastatuak dira. Izan ere, birgaitzean asko erabiltzen dira eta hainbat material eta eraikuntza-soluzio erabil ditzakete. Horien artean nabarmenenak honako hauek 
dira: fatxada aireztatuen sistemak, kanpo-isolamendu termikorako sistemak (SATE), barruko isolamendurako sistemak eta ganbera-injekzio bidezko isolamendua.

\subsection{Birgaitze-teknika motak}

\subsubsection{Fatxada aireztatua}

Isolamendu-sistema hauetan, esku-hartzea itxituraren kanpoaldetik egiten da. Eraikin berriak eta birgaitu beharreko eraikinak termikoki isolatzeko erabiltzen da. Ganbera bat gehitzen da airearen zirkulazioa ahalbidetzeko, eta isolamendu termiko bat ezartzen da kanpoaldetik (4. irudia). Horrela, berotze- eta hozte-sisteman energia-kontsumoa asko aurreztea lortzen da $[23,24]$.

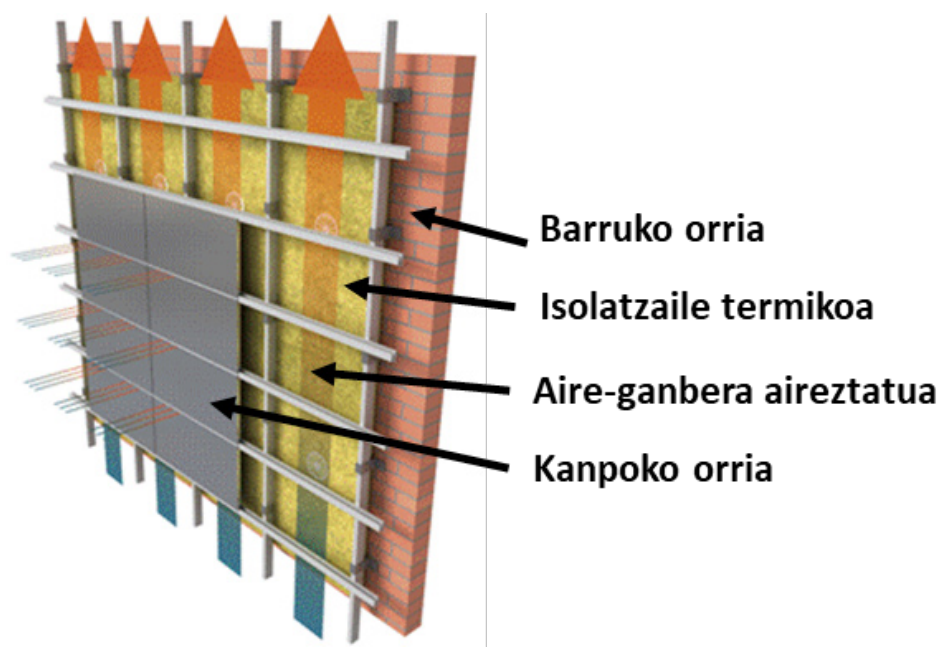

4. irudia. Fatxada aireztatua.

\subsubsection{Kanpo-isolamendu termikorako sistemak (SATE)}

Gaur egun, kanpo-isolamendu termikorako sistemak (SATE) eta fatxada aireztatuen sistemak dira erabilienak. SATE sistemek abantailak eskaintzen dituzte ikuspuntu termikotik, ekonomikotik eta funtzionaletik, aplikatzen errazak direlako [25].

Fatxaden sistema integral bat da; hau da, osagai bakoitza multzo baten parte da, eta, beraz, osagaiak batera sortu eta probatu behar dira. Sistema hauen erresistentzia termikoak $1 \mathrm{~m}^{2} \mathrm{~K} / \mathrm{w}$ edo handiagoa izan behar du, ETAG 004 gidan eta UNE-EN 13499 eta UNE-EN13500 [26, 27] arauetan adierazitakoaren araberakoa izan. 




5. irudia. Kanpo-isolamendu termikorako sistemak (SATE).

Xafla isolatzailea itsasgarri eta finkapen mekaniko bidez finkatzen da hormara [28]. Xafla isolatzailea babesteko isolatzaileari estaldura bat aplikatzen zaio zuzenean. Estaldura mortero-geruza bat edo batzuk izaten dira, eta horietan beira-zuntzezko sare bat jarri ohi da. Sare horrek morterozko akabera izan dezake, edo adreilu akrilikoak, buztinezko edo harrizko zeramikoak [29] (5. irudia).

\subsubsection{Barruko isolamendurako sistemak}

Sistema hauek etxebizitza termikoki isolatzeko erabiltzen dira, barruko konfort termikoa eta akustikoa handituz eta eraikinaren efizientzia termikoa hobetuz. Sistema hauetan, material isolatzailea etxebizitzaren barruko hormetan jartzen da, eta igeltsu ijeztutako plaken bidez estaltzen da gehienetan. Azkenik, akaberako pintura-geruza bat aplikatzen da.

Barneko isolamendu termikoko sistemarik ohikoenak zuzeneko sistema trasdosatua eta trasdosatu autosostengagarria dira. Trasdosatu zuzenaren sisteman, isolatzaileak eta igeltsu ijeztutako plakak multzo bat osatzen dute, eta multzo hori etxebizitzaren barruko hormen gainean jartzen da zuzenean. Trasdosatu autosostengagarriaren sisteman, aldiz, igeltsu ijeztuko plakak egitura baten gainean finkatzen dira, eta isolatzailea plaken eta etxebizitzaren barruko hormaren artean jartzen da (6. irudia). 


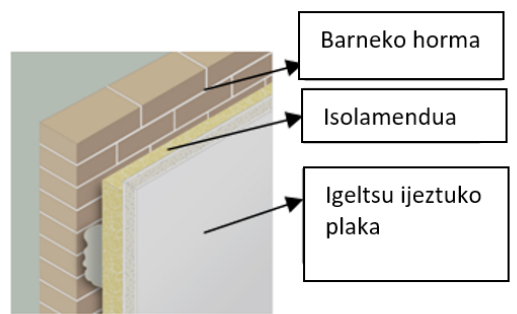

Trasdosatu zuzeneko barne sistema.



Trasdosatu autosostengagarriko barne sistema.

6. irudia. Trasdosatu bidezko barne-sistemak.

\subsubsection{Ganbera-injekzio bidezko isolamendua}

Sistema hauetan, eraikinaren aire-ganberaren barruan material isolatzaile bat injektatzen edo intsuflatzen da, eraikinaren efizientzia energetikoa hobetzeko (7. irudia). Esku-hartzea etxebizitzaren barrualdetik edo eraikinaren kanpoaldetik egin daiteke, baldin eta fatxadak aire-ganbera badu eta ganbera hori irisgarria bada.

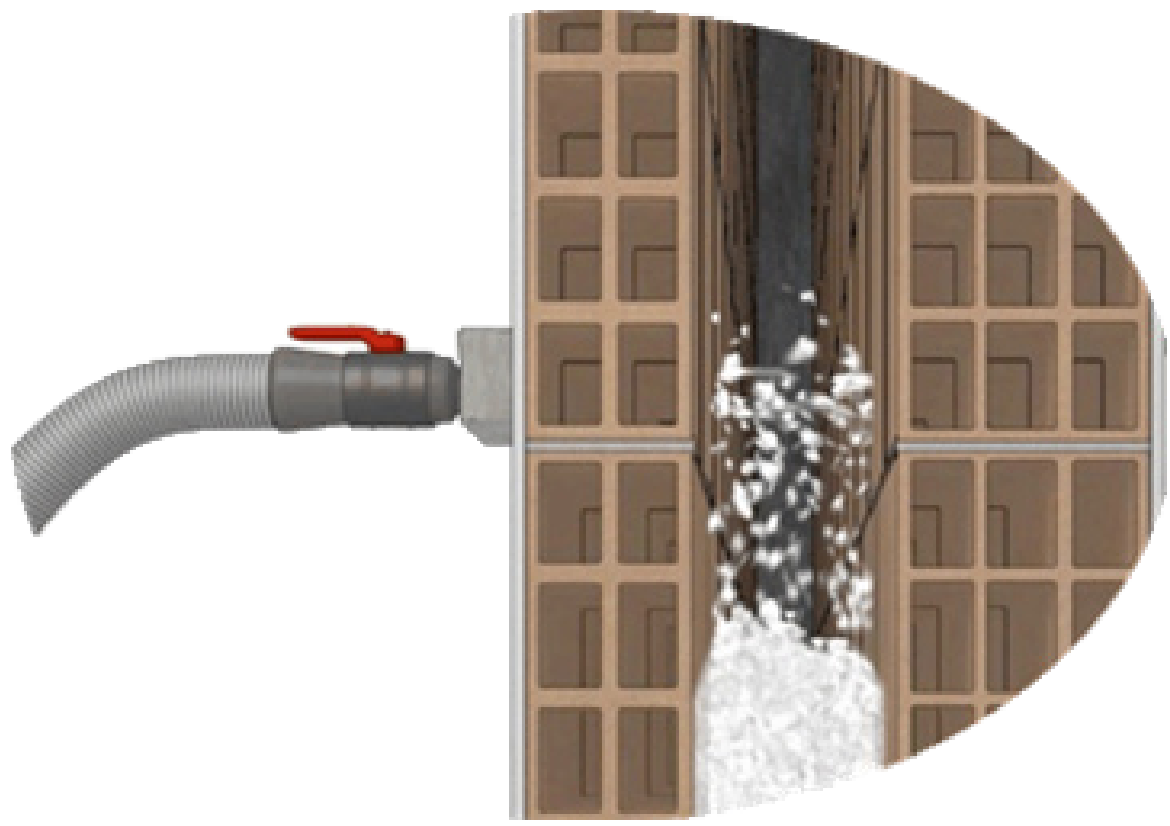

7. irudia. Ganbera-injekzio bidezko isolamendua. 


\subsection{Birgaitze-tekniken azterketa, jasangarritasun-irizpideen arabera}

Ondoren, birgaitze-teknika hauek 2. taulan agertzen diren jasangarritasun-irizpideak kontuan hartuta aztertuko dira.

Ekonomiaren ikuspuntutik, sistemarik merkeenak ganbera-injekzio bidezko isolamendu-sistemak dira. Material isolatzailea baino ez da erabiltzen, eta, horregatik, ia ez du hondakinik sortzen. Barruko isolamendurako sistema ere merkeenetako bat da. Kanpoko isolamendu-sistema (SATE eta fatxada aireztatua) batekin alderatuz, inbertsio-kostua \% 50 inguru txikiagoa da [23]. Kanpoko isolamendu-sistemak alderatuta, fatxada aireztatuen inbertsioaren kostua SATE sistemena baino handiagoa da. Halaber, fatxada aireztatuen instalazioa SATE sistemena baino konplexuagoa da. Izan ere, azken horiek sistema integratuak dira eta ez dute inolako egiturarik behar kanpoko akabera instalatzeko.

Ingurumena kontuan hartuta, fatxada aireztatuaren kasuan, duen aireganberaren ondorioz, hozte-kontsumoan lortzen den aurrezpena handiagoa da SATE sistemen aldean. Beraz, klima beroetan, eraginkorragoa da fatxada aireztatua [24]. Baina EAEko etxebizitzetan hozte-erabilera \% 1,7koa baino ez da. Beraz, datu horrek ez du eraginik izango birgaitze-sistema jasangarriena aukeratzeko orduan. SATE eta fatxada aireztatuen sistemek eraikineko zubi termiko gehienak erraz konpontzeko eta inguratzailea termikoki hobetzeko aukera ematen dute [30]. Izan ere, eraikinaren kanpoaldea guztiz estaltzen eta isolatzen da, eta eraikinaren inguratzailearen geometrietara egokitzen da etengabe [29]. Fatxada kanpoaldetik isolatzean, ekidin egiten dira gainazalekoak eta interstizialak diren kondentsazioak, eta hobetu egiten da etxebizitzaren barruko konfort termikoa. Barruko isolamendurako eta ganbera-injekzio bidezko isolamendu-sistemetan, aldiz, ez dira zubi termikoak saihesten. Izan ere, konponbide ez-jarraituak dira; hau da, isolamenduak ez du eraikinaren inguratzailea guztiz estaltzen. Barnealdean lortutako energia-aurreztea eta konfort termikoa soluzio jarraituetan baino txikiagoak izango dira [31]. Halaber, ganbera-injekzio bidezko isolamendu-sistemetan, aire-ganberaren lodierak mugatu egiten du isolatzailearen lodiera. Ganberaren lodieraren arabera, aurreztutako energia txikiagoa izan daiteke fatxadaren barruko isolamendu-sistemetan baino [32].

Ikuspegi sozialetik, barruko isolamendurako sistemetan, beste sistemetan ez bezala, beharrezkoa da obrak irauten duen bitartean etxebizitza uztea [29]. Gainera, behin instalazioa eginda, espazioa galtzen da barruan. Horrek guztiak eragozpenak sortzen dizkie maizterrei, obra osoan zehar etxebizitza osorik edo zati batean uztea beharrezkoa delako, hormetara sartzeko altzariak mugitu behar direlako, eta kalte nagusietako bat etxebizitzan espazio erabilgarria galtzea delako [33]. EAEko metro karratuaren prezioa 2.765 eurokoa dela eta batez besteko azalera erabilgarria $87,3 \mathrm{~m}^{2}$-koa dela kontuan hartuta, aintzat hartu beharrekoa da azken faktore hori. 
SATE eta fatxada aireztatuen sistemetan, jatorrizko fatxadaren estetika hobetzea lortzen da, baita eraikinaren balioa handitzea ere. Horrek gaztetu egiten du eraikinaren eta kokatuta dagoen inguruaren itxura estetikoa [29]. Baina eraikinaren jatorrizko fatxada aldatzeak arazoak ekar ditzake ingurunera egokitzeko mailan. Sistema hauetan, aukeratutako kanpo-estaldurak zehaztuko du eraikinaren azken estetika. SATE sistemetan ez bezala, fatxada aireztatuetan aukera zabala dago kanpoko estaldurak aukeratzeko orduan. Estaldura azpiegituraren gainean doanez, eta ez isolatzailearen gainean, material desberdinetan egindako plakak kanpo-estaldura gisa erabiltzea ahalbidetzen du. Erabilitako estaldura motak zehaztuko ditu fatxada aireztatuen sistemen azken prezioa eta ingurunera egokitzeko maila. Gainera, eraikinaren kanpoko itxura aldatu egiten denez, ezin da erabili ondare arkitektoniko gisa katalogatutako eraikinetan [34]. Barruko isolamendurako eta ganbera-injekzio bidezko isolamendu-sistemak, aldiz, guztiz egokituko dira ingurunera egokitzeko mailara eta edozein eraikinetan erabil daitezke. Izan ere, sistema hauetan fatxada ez da aldatzen.

Kanpo-sistemetan (SATE eta fatxada aireztatuen sistemak) eta ganberainjekzio bidezko isolamendu-sistemetan aldamioak erabiltzen dira eta jabeen arteko adostasuna behar da. Horrek eragozpenak sor diezazkieke jabeei eta oinezkoei.

\section{ONDORIOAK}

Bizitegi-sektorea energia-kontsumitzaile eta $\mathrm{CO}_{2}$-igorle garrantzitsua da, bai Europan eta bai Estatuan. Gainera, energia-baliabideen eskasia eta energia-inportazioekiko mendekotasuna gero eta handiagoak dira. Berotegi-efektuko gasak mugatu egin behar dira, eta krisi ekonomikoak gainditu. Hori dela eta, neurriak hartu behar izan dira, eraikuntzaren sektorean energia-kontsumoa eta iturri berriztagarrietatik sortutako energien erabilera kontrolatzeko.

EAEko etxebizitza-parkea Europar Batasuneko zaharrenetakoa da. Gainera, eraikinen \% 90 inguru pobreak dira energetikoki, 2006ko EKT (energia-efizientziari buruzko gutxieneko eskakizunak jasotzen dituen araudia) indarrean jarri aurretik eraiki zirelako. Hortaz, eraikin horiek, epe labur edo ertainean, birgaitu egin beharko dira energetikoki.

Europan, Estatuan eta Euskal Autonomia Erkidegoan, eraikinen birgaitze energetikoa sustatzeko ekimenak sortu dira. Ekimen horiek alderdi ekonomikoan bakarrik zentratu dira, inbertsiorako laguntza-planen bidez. Baina, plan horiez gain, beharrezkoa da birgaitze-prozesuan parte hartzen duten eragile guztiak inplikatzea, hala nola eraikinen erabiltzaileak. Izan ere, gaur egun, neurri handi batean, eraikinen erabiltzaileen artean ez dago energiaren kontsumoaren inguruko kontzientziaziorik. Gainera, 
erabiltzaileek kontsumoaren inguruan hartu dituzten ohiturak ez dira egokienak.

Eraikinaren fatxadaren birgaitze energetikoak energia-kontsumoa eta $\mathrm{CO}_{2}$ isuriak murriztea dakar. Horretarako, hainbat birgaitze-teknika daude, eta, erabakiak hartzen laguntzeko, jasangarritasun-irizpideak erabiltzea planteatzen da. Irizpide horiek birgaitze-sistemen alderdi ekonomikoak, ingurumenekoak eta sozialak hartzen dituzte kontuan.

Ikuspegi ekonomikotik, inbertsioaren errentagarritasuna kontuan hartuta, SATE da teknikarik egokiena. Izan ere, fatxada aireztatua baino merkeagoa da, eta, soluzio jarraitua denez, energia gehiago aurrezten da. Ingurumenaren aldetik ere oso egokia da teknika hau. Baina, ikuspegi sozialetik, barruko isolamendurako sistemak sortzen ez dituen eragozpenak izan ditzake, hala nola jabeen arteko adostasunaren beharra. Teknikarik desegokiena, berriz, jasangarritasunaren ia irizpide gehienak kontuan hartuta, ganbera-injekzio bidezko isolamendua da. Fatxadaren kanpoaldetik isolatzeko esku-hartzeak baztertzen direnean erabiltzea gomendatzen da, hala nola fatxada babestua denean edo eraikinaren jabeen artean adostasunik ez dagoenean. Gainera, isolamendu termikoko sistema baten ondorioz etxebizitzaren barruan lekurik galdu nahi ez denean bakarrik da gomendagarri. Hortaz, gainerako birgaitze-soluzioak baztertzen direnean balora daiteke sistema horren erabilera.

Artikulu honetan jasotzen den lana tokikoa da. Hemen azaldutakoa beste ingurune batean erabili ahal izateko, aldatu egin behar lirateke inguruneko baldintzak, hala nola herrialdeak daukan araudi propioa, lan-teknika ohikoenak eta abar. Gainera, artikulu honetan birgaitze-teknikak bakarrik hartu dira kontuan. Hortaz, etorkizuneko ikerketa-ildo bezala plantea daiteke birgaitze-prozesuan erabiltzen diren materialak kontuan hartzea; horrela, materialik jasangarriena aukeratu ahal izango litzateke.

\section{ESKER ONAK}

Autoreek eskerrak eman nahi dizkiete Eusko Jaurlaritzako IT1314-19, UPV/EHUko GIU19/029 eta SAREN ikerketa-taldeek emandako laguntzari eta UPV/EHUko PPGA20/26 finantzaketari.

\section{BIBLIOGRAFIA}

[1] European Parliament. 2018. «Directive 2018/844/EU of the European Parliament and of the council of 19 June 2018 on the energy performance of buildings (recast)». Official Journal of the European Communities, 61, 75-91. 
Euskal Autonomia Erkidegoan kokatuta dauden eraikinen birgaitze energetikoa: birgaitze-teknikak eta erabakia hartzeko jasangarritasun-irizpideak

[2] Hernández SÁnchez, J. M. 2012. «Energy consumption and associated emissions of residential sector». 15th International Congress on Project Engineering. Asociación Española de Ingeniería de Proyectos. ISBN978041562128-1.

[3] Sech-Spahousec, P. 2011. «Análisis del consumo energético del sector residencial en España. Informe Final». Instituto para la Diversificación y Ahorro de Energía.

[4] Garcia-Hooghuis, A., NeILA, F.J. 2013. «Transposition of the 2002/91/EC and 2010/31/EU» Energy Performance Building Directive» in the EU Members States. Consequences and implications». Informes de la construccion, 65, 289-300. DOI: 10.3989/ic.12.017.

[5] Ma, Z., Cooper, P., Daly, D., Ledo. L. 2012. «Existing building retrofits: Methodology and state-of-the-art». Energy and buildings, 55, 889-902. https://doi.org/10.1016/j.enbuild.2012.08.018.

[6] Egiluz Ellakuria, Z. 2017. «Euskal Autonomia Erkidegoan kokatuta eta EKT-a indarrean sartu baino lehen eraikitako bizitegi-eraikinetako fatxaden birgaitze jasangarrirako metodologia». $\mathrm{PhD}$ thesis, Universidad del País Vasco/ Euskal Herriko unibertsitatea (UPV/EHU), Bilbao, Spain.

[7] EsPaÑa. Ministerio dE LA Vivienda. 2006. «Código técnico de la edificación (CTE): Real Decreto 314-2006, de 17 de marzo, por el que se aprueba el Código Técnico de la Edificación (CTE)». Boletín Oficial del Estado.

[8] Ministerio De Fomento. 2019. «Real Decreto 732/2019, de 20 de diciembre, por el que se modifica el Código Técnico de la Edificación, aprobado por el Real Decreto 314/2006, de 17 de marzo». Boletín Oficial del Estado.

[9] Instituto Nacional de Estadísticas, Censos de Población y Viviendas. 2011. https://www.ine.es/censos2011_datos/cen11_datos_inicio.htm (eguneratze data: 2021 ko iraila).

[10] Eustat, Euskal Estatistika ERAKundEA-InStituto Vasco de Estadística, VIVIENDAS FAMILIARES DE LA C.A. DE EUSKADI POR ÁMBITOS TERRITORIALES. https://www .eustat.eus/elementos/ele0011300/viviendas-familiares-de-laca-de-euskadi-por-ambitos-territoriales-segun-caracteristicas-estructurales/ tbl0011354_c.html (eguneratze data: 2020ko urtarrila).

[11] ObSERVATORIO VASCO DE LA VIVIENDA. 2015. «Informe de Evaluación de la Política de Rehabilitación 2014». Gobierno vasco.

[12] Gobierno Vasco. 2012. «Hoja de ruta de edificación sostenible del País Vasco. Bultzatu 2025». Gobierno vasco.

[13] Gobierno de España, Plan de RecuPERACión, Transformación y ReSILIENCIA. https://planderecuperacion.gob.es/ (eguneratze data: 2021 eko abendua).

[14] Eustat, Euskal Estatistika Erakundea-Instituto Vasco de Estadística, Medio ambiente - Familias. https://www.eustat.eus/estadisticas/ tema_456/opt_0/ti_medio-ambiente---familias/temas.html (eguneratze data: 2021ko ekaina).

[15] Jefatura Del Estado. 2015. «Ley 8/2013, de 26 de junio, de rehabilitación, regeneración y renovación urbanas». Boletín Oficial del Estado. 
[16] RuÁ, M. J., LóPEZ-MesA, B. 2012. «Spanish energy rating labelling of buildings and its cost implications». Informes de la Construcción, 64, 307-318. DOI: $10.3989 /$ ic.11.028.

[17] WWF/AdEnA. 2010. «Potencia de ahorro energético y reducción de emisiones de CO2 del parque residencial existente en España en 2020». WWF/ Adena.

[18] Omrany, H., Ghaffarianhoseini, A., Ghaffarianhoseini, A., RaAhemifar, K., ToOKey, J. 2016. «Application of passive wall systems for improving the energy efficiency in buildings: A comprehensive review». Renewable and Sustainable Energy Reviews, 62, 1252-1269. https://doi.org/10.1016/j. rser.2016.04.010.

[19] Mavromatidis, L.E., Bykalyuk, A., Lequay, H. 2013. «Development of polynomial regression models for composite dynamic envelopes' thermal performance forecasting». Applied Energy, 104, 379-391. https://doi. org/10.1016/j.apenergy.2012.10.045.

[20] Peippo, K., Lund, P.D., Vartiainen, E. 1999. «Multivariate optimization of design trade-offs for solar low energy buildings». Energy and buildings, 29, 189-205. https://doi.org/10.1016/S0378-7788(98)00055-3.

[21] Tupenaite, L., Zavadskas, E.K., Kaklauskas, A., Turskis, Z., Seniut, M. 2010. «Multiple criteria assessment of alternatives for built and human environment renovation». Journal of civil engineering and management, 16, 257-266. DOI:10.3846/jcem.2010.30.

[22] Egiluz, Z., Cuadrado, J., Kortazar, A., Marcos, I. 2021. « Multi-Criteria Decision-Making Method for Sustainable Energy-Saving Retrofit Façade Solutions». Sustainability, 13(23), 13168. https://doi.org/10.3390/ su132313168.

[23] Kolaitis, D.I., Malliotakis, E., Kontogeorgos, D.A., Mandilaras, I., KATsourinis, D.I., FounTI, M.A. 2013. «Comparative assessment of internal and external thermal insulation systems for energy efficient retrofitting of residential buildings». Energy and buildings, 64, 123-131. https://doi. org/10.1016/j.enbuild.2013.04.004.

[24] Alonso, C., Oteiza, I., García-Navarro, J., Martín-Consuegra, F. 2016. «Energy consumption to cool and heat experimental modules for the energy refurbishment of façades. Three case studies in Madrid». Energy and buildings, 126, 252-262. https://doi.org/10.1016/j.enbuild.2016.04.034.

[25] Barreira, E., De Freitas, V.P. 2013. «Experimental study of the hygrothermal behaviour of External Thermal Insulation Composite Systems (ETICS)». Building and environment, 63, 31-39. https://doi.org/10.1016/j. buildenv.2013.02.001.

[26] UNE, NoRMALIZACIÓN ESPAÑOLA. 2004. «UNE-EN 13500. Productos aislantes térmicos para aplicaciones en la edificación. Sistemas compuestos para aislamiento térmico externo (ETICS) basados en lana mineral. Especificación». UNE. 
[27] UNE, NoRmalización ESPAÑOlA. 2004. «UNE-EN 13499.Productos aislantes térmicos para aplicaciones en la edificación. Sistemas compuestos para aislamiento térmico externo (ETICS) basados en poliestireno expandido. Especificación». UNE.

[28] Nilica, R., Harmuth, H. 2005. «Mechanical and fracture mechanical characterization of building materials used for external thermal insulation composite systems». Cement and Concrete Research, 35, 1641-1645. https://doi. org/10.1016/j.cemconres.2005.04.001

[29] IDAE. INSTITUTO PARA LA DIVERSIFICACIÓN Y AHORRO DE LA ENERGÍA. MINISTERIO DE Industria, ENERGía y TuRISMo. 2012. «Sistemas de Aislamiento Térmico Exterior para la rehabilitación de la envolvente térmica de los edificios». IDAE.

[30] Mandilaras, I., Atsonios, I., Zannis, G., Founti, M. 2014. «Thermal performance of a building envelope incorporating ETICS with vacuum insulation panels and EPS». Energy and buildings, 85, 654-665. https://doi. org/10.1016/j.enbuild.2014.06.053.

[31] IDAE. INSTITUTO PARA LA DIVERSIFICACIÓN Y AHORRO DE LA ENERGÍA. MinisTERIO DE INDUSTRIA, ENERGÍA Y TURISMO. 2008. «Guía Técnica para la Rehabilitación de la Envolvente Térmica de los Edificios. Soluciones de Aislamiento con Lana Mineral». IDAE.

[32] IDAE. INSTITUTO PARA LA DIVERSIFICACIÓN Y AHORRO DE LA ENERGÍA. MiNISTERIO DE INDUSTRIA, ENERGÍA Y TURISMO. 2008. «Soluciones de aislamiento con poliuretano (PUR)». IDAE.

[33] Tink, V., Porritt, S., Allinson, D., Loveday, D. 2018. «Measuring and mitigating overheating risk in solid wall dwellings retrofitted with internal wall insulation». Building and environment, 141, 247-261. https://doi. org/10.1016/j.buildenv.2018.05.062.

[34] Forman, T., TweED, C. 2014. «Solid wall insulation retrofit in UK dwellings: Critical factors affecting management and quality». Proceedings of the 30th Annual ARCOM Conference, 1367-1376. 
